\title{
Researcher fights suspension over funds
}

[SAN DIEGO] The University of California at San Francisco (UCSF) has suspended for three years an internationally known anaesthesiology researcher who diverted millions of dollars from drug company grants to a non-profit foundation that he directed.

But before the academic suspension could begin on 1 June, the researcher, Dennis Mangano, filed a lawsuit in state court in a bid to block the rare academic disciplinary action in the long-running case (see Nature $385,377 ; 1997)$.

University attorneys said they had delayed imposing the suspension until after court proceedings because Mangano is on unpaid, stress-related leave from his tenured professorship at UCSF.

But he reportedly continues to practice medicine at the VA Medical Center in San Francisco, where he was a vice-chairman of anaesthesia.

The Mangano case is being closely watched at the University of California, where non-profit foundations set up by academic researchers have come under scrutiny. Such foundations came into vogue about 20 years ago to enable benefactors to contribute to specific research projects, and professors to fund immediate research needs.

A number of foundations created by University of California professors grew to the million-dollar range, and the Ischemia Research and Education Foundation (IREF), founded and directed by Mangano, became one of the biggest.

A UCSF audit estimated that more than $\$ 50$ million in indirect costs were diverted to IREF. In his lawsuit, Mangano says IREF collected indirect expenses for possible future needs at an independent research site.

Following academic reviews and a management audit, court records say that UCSF Chancellor Michael Bishop notified Mangano on 3 May of his suspension after a university committee had found that he "repeatedly made extensive use of university resources" to benefit his foundation and for "purposely defrauding sponsors of drug trials". The committee also found that Mangano harassed and intimidated UCSF colleagues.

Mangano's attorneys declined to be interviewed on the suspension or the lawsuit, which was filed on 28 May in San Francisco Superior Court. They have sought to keep sealed the 65-page lawsuit detailing the five years of the academic disciplinary process and fighting over millions of dollars in research funds.

But Nature obtained a copy of the lawsuit after it was revealed at this month's meeting of the University of California Board of Regents.

Objecting to the suspension, Mangano's attorneys say in court records that he was denied due process, that the disciplinary academic committee's decisions are not supported by the evidence, and that university rules regarding non-profit foundations were not violated. The lawsuit seeks to have the suspension voided and Mangano paid damages for what his attorneys called "this virtually unprecedented discipline".

"The suspension will devastate [his] academic career and will damage his reputation in the professional community beyond repair," the lawsuit says. The university has until next week to respond.

In January 1997, IREF paid \$25 million to settle a lawsuit over the alleged misappropriation of indirect costs associated with international drug studies conducted by Mangano and IREF.

The lawsuit had been filed in 1994 by physiologist Charles A. Richardson, a former colleague of Mangano's, invoking a seldomused California law for whistleblowers to expose misappropriations from the state.

The university received $\$ 19.2$ million of the settlement, in which IREF admitted no wrongdoing. Richardson got $\$ 1.5$ million and his attorneys $\$ 4.3$ million; payments the whistleblower law permits to encourage the reporting of potential improprieties.

But in a peculiar twist, Richardson lost his job as a UCSF assistant adjunct professor less than a year later. Last February, Richardson filed a lawsuit against the university and UCSF's chairman of anaesthesia, Ronald D. Miller, for retaliation, alleging he was forced out for challenging practices associated with non-profit foundations.

Richardson sought to have some of the money recovered from IREF used to support his research projects, which were disrupted when he challenged Mangano. University officials, who rejected Richardson's request, have denied any retaliation.

During Richardson's lawsuit and his most recent case, Mangano argued that that his non-profit corporation activities were no different to other UCSF professors. Apparently to support this, Mangano's attorney persuaded Miller to acknowledge during a deposition that the anaesthesia chief used $\$ 17,000$ from a foundation with which he was associated to renovate his UCSF office. In his deposition, Miller said he intended to pay the foundation back. Miller could not be reached for comment last week.

John Lundberg, the university's deputy general counsel, says that the suspension is appropriate because Mangano's “conduct was beyond the pale".

Lundberg said a tactical decision was made to settle the whistleblower's lawsuit in 1997 rather than fight for the remainder of the money. Most of the other foundations started by University of California professors have been required to direct their funds to the university's foundations.

Since the Richardson lawsuit, Mangano has been involved in several other lawsuits over the handling of IREF funds. In one, he is accused of improperly using more than $\$ 300,000$, which he denies. He now claims the foundation owes him $\$ 1.4$ million. RexDalton

\section{First-born telescopic twin starts to deliver}

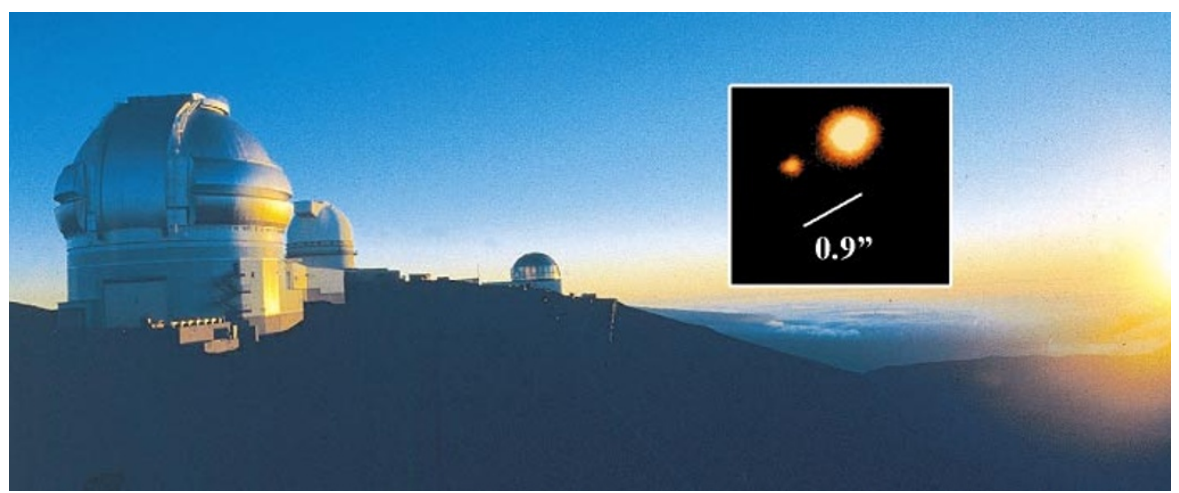

[LONDON] Astronomers have begun to receive pictures from one of the twin infrared telescopes, Gemini North (above), based at Mauna Kea in Hawaii, which is being dedicated this week (25 June). One of the first images is of the planet Pluto and its moon Charon (inset).

The ground-based infrared telescope is more than twice as powerful as the Hubble space telescope and has an eight-metre mirror. Yet the twin Gemini telescopes will cost only $\mathfrak{E} 111 \mathrm{~m}$ (US\$176 million), a fraction of Hubble's $\$ 3$ billion.

The project is an international effort, with most support coming from the United States and Britain. Gemini South is under construction at Cerro Pachon, Chile.

Gemini is able to partially correct for atmospheric distortions producing highquality images. On Monday this week, astronomers received a picture with a resolution of 0.08 arcseconds. Natasha Loder 